\title{
II ENCONTRO NACIONAL DE ENSINO DE PAISAGISMO EM ESCOLAS DE ARQUITETURA E URBANISMO NO BRASIL
}

\author{
DR. SILVIO SOARES MACEDO
}




\section{RESUMO}

$E_{\text {sto }}$ tro Nacional de professores de paisagismo em Escolas de Arquitetura Urbanismo no Brasil, destacando-se entre estes a recomendação de seis pontos básicos para o ensino do paisagismo. Estes são: Fundamentos Conceituais, História do Paisagismo, Paisagem Urbana, Morfologia da Paisagem, Processo Criativo da Paisagem: métodos e técnicas e Construção da Paisagem.

\section{ABSTRACT}

$T_{\text {his }}$ professours in the Brazilian Architecture and Urban Schools, wich took place in São Paulo at the Faculdade de Arquitetura e Urbanismo da USP in october 1995. It presents a synthesis of this process and the main conclusions of the seminar. 


\begin{abstract}
A realização do II ENEPEA foi um marco importante na sistematização do ensino de paisagismo em nível superior no Brasil, em especial nas escolas de arquitetura, pois pela primeira vez se conseguiu definir os tópicos fundamentais, em número de 06 , em termos de conteúdos, a serem ministrados em disciplinas básicas sobre o assunto.
\end{abstract}

\title{
Estes compreendem:
}

1. Fundamentos conceituais-no qual o aluno aprenderá noções básicas sobre paisagem, paisagismo, planejamento da paisagem e seus métodos. Paisagem urbana e seus elementos componentes, espaços livres de edificação e urbanização, etc.

2. História do paisagismo - abrangendo as origens do pensamento e do projeto paisagístico moderno e contemporâneo, dando-se ênfase na sua relação com a produção da cidade dos séculos 19 e 20 e com a questão ambiental contemporânea.

3. Paisagem urbana - envolvendo a análise e a prospecção da paisagem urbana brasileira, seus padrōes morfológicos e seus espaços livres.

4. Morfologia da paisagem - compreendendo o estudo e a compreensão das estruturas paisagísticas nas diversas escalas de abrangência, do território ao lugar, da cidade às áreas ecologicamente frágeis.

5. Processo criativo da paisagem: métodos e técnicas objetivando introduzir e desenvolver a capacidade de criação individual de espaços e lugares para um futuro próximo, apresentando-se no caso os procedimentos tradicionais de projeto e paisagismo e as novas opções em desenvolvimento.

6. Construção da paisagem - apresentando técnicas de desenvolvimento de projeto e planejamento paisagístico nas suas escalas principais.

Estes conteúdos foram exaustivamente discutidos no evento, mas aparecem nos seu Anais e documento final apenas em 
forma de uma simples lista, de modo a permitir a cada escola o desenvolvimento de uma linha própria de ensino tanto em nível conceitual como metodológico. Considerou-se, na oportunidade, esta postura mais ética possivel.

Esta foi uma posição estratégica da comissão de redação dos trabalhos, tendo sido aprovada pela plenária final do evento. Con-siderou-se na oportunidade que mesmo a despeito da intensidade e profundidade das discussões entabuladas, o consenso ainda não existia para tal tipo de detalhamento.

Os seis pontos foram então uma síntese das discussões ocorridas durante o evento, nas suas sessões de apresentação e discussão sobre o assunto, e que ocuparam praticamente $70 \%$ do tempo disponível.

A definição dos pontos cumpriu o objetivo principal do evento, que foi o de estabelecer subsídios teóricos mínimos para a abertura, consolidação e manutenção de disciplinas de Paisagismo em Escolas de Arquitetura e Urbanismo no Brasil, já que de acordo com a Portaria n. 1.770/94 do Ministério da Educação e do Desporto (Vide $1^{1}$ circular do ENEPEA), o ensino do Paisagismo passa a ser obrigatório nestas escolas. Vale esclarecer que o Brasil conta hoje com mais de 60 escolas de arquitetura e urbanismo e quase metade não possuem nenhuma matéria sobre o assunto e uma grande maioria possui uma só disciplina, colocada aleatoriamente na grade curricular.

Neste ano de 1995 e nos próximos, muitas escolas estão revendo seus currículos de acordo a reestruturá-los a uma nova realidade e paralelamente tem-se a notícia da abertura de cerca de 70 novos cursos, reforçando estes fatos à oportunidade do evento.

Além destes pontos as discussões dos grupos de trabalho levaram:

1 A formulação de prinçípios básicos a serem considerados quando da aplicação das disciplinas que seriam: 
- O arquiteto e urbanista em sua formação deve se apropriar das bases sociais, estéticas e tecnológicas do projeto da paisagem.

- O ensino de paisagismo deve contemplar a ordenação de objetos e suas relações.

2. A indicação de uma lista de 11 recomendações de apoio à implementação técnica das disciplinas. A mais importante delas, na minha opinião, foi a terceira (vide listagem a seguir) que sugere 180 horas/aula como o espaço tempo mínimo de duração das matérias de paisagismo em um curso de arquitetura e urbanismo.

Esta recomendação, ao estabelecer um patamar horário mínimo necessário implica de um modo positivo nos seguintes fatos:

- Consolidação das disciplinas existentes;

- possibilidade de abertura de novas disciplinas;

- a existência de 02 a 03 disciplinas de paisagismo por curso (no mínimo).

As recomendações são as seguintes:

Devem ser objetivadas integrações disciplinares de acordo com a necessidade de cada escola.

Os diversos temas de paisagismo devem obedecer à uma seqüenciação lógica.

Deve ser considerada a adequada inserção da(s) disciplina(s) de paisagismo no currículo dos cursos de arquitetura e urbanismo, atendendo à duração mínima prevista no I ENEPEA (180 horas).

O estudo da vegetação deve ser adequadamente contemplado pela(s) disciplina(s) de paisagismo.

Devem ser realizadas viagens de análise de projetos e de obras de paisagismo. 
A abordagem da(s) disciplina(s) de paisagismo deve iniciar pelo nivel intra-urbano, atingindo os níveis urbano e regional.

O conteúdo das disciplinas de paisagismo deve enfatizar a função social do mesmo.

As necessárias atividades de ensino, pesquisa e extensão devem alimentar o conteúdo da(s) disciplina(s) de paisagismo.

Deve ser organizado o acervo de trabalhos produzidos nas escolas (incluindo os de TGl), à luz das metodologias adotadas pelos docentes.

Deverá ser instituída uma Comissão Permanente de Ensino de Paisagismo em escolas de arquitetura e urbanismo no Brasil, coordenada com as deliberações do XIII Encontro Nacional sobre Ensino de Arquitetura, realizado em Brasília de 08 a 12 de outubro de 1995.

As disciplinas, que pertencem a outros campos de conhecimento, devem ser objeto de disciplinas complementares, optativas ou de especialização.

\section{O EVENTO - PROCEDIMENTOS}

As atividades foram organizadas de modo a privilegiar a discussão e o conhecimento dos conteúdos necessários para o ensino do paisagismo em cursos ou escolas de arquitetura e urbanismo. Para tanto a comissão organizou e dividiu o evento do seguinte modo:

Comunicações sobre conteúdos de disciplinas - foram selecionados 12 trabalhos, apresentados em duas sessões pela manhã, destacando-se os trabalhos das professoras Helena Degreas (UNIP), Alina Santiago (UFSC) e Maria Angela F. P. Leite (FAUUSP), cujos conteúdos nortearam todas as discussões posteriores. Cada trabalho foi apresentado em 15 minutos, seguindo-se a uma discussão geral após o encerramento dos trabalhos. 
Grupos de trabalho sobre conteúdos de disciplinas-o conjunto de participantes foi dividido em 05 grupos, de acordo com recomendação da coordenação, que ao final dos trabalhos apresentaram individualmente os seus resultados, tendo sido compatibilizados por uma comissão mista no dia 05 de outubro. Estes grupos produziram uma excelente discussão e o resultado final está sintetizando nas recomendações do evento.

Conferências - foram convidados 5 professores de renome nacional para ministrar conferências que tinham como objetivo dar um apoio conceitual e técnico à discussão dos diversos grupos de trabalho. Foram eles:

- Dra. Miranda M. Magnoli - professora titular da FAUUSP, organizadora da área de paisagismo da FAUUSP e a maior teórica sobre $o$ assunto paisagismo no Brasil, que ministrou a conferência "Ensino de paisagismo em escolas de arquitetura e urbanismo no Brasil", enfocando a definição do objeto de trabalho da disciplina.

- Profa. Maria Elisa Meira - da UFFL/ABEA/MEC - que deveria discorrer sobre "O novo curriculum mínimo dos cursos de arquitetura e urbanismo", mas que por motivos de força maior não pode comparecer ao evento. No caso a professora coordenou os trabalhos de formulação da Portaria n. 1.770/94 do MEC.

- Dr. Vicente del Rio - da UFRJ - um dos maiores especialistas do país em Desenho e Paisagem Urbana e que ministrou a conferência "Desenhoda paisagem: Arte, simulação, humanismo, cibernética", discutindo questōes básicas da produção da paisagem urbana brasileira contemporânea.

- Arqta. Rosa Kliass - mestre pela FAUUSP e, com certeza, atualmente a paisagista brasileira de maior penetração internacional devido aos seus trabalhos junto a IFLA - International Federation of Landscape Architects, e mentora de diversos cursos de extensão e responsável por uma produção importante de arquitetura paisagística no país, que ministrou a conferência "Paisagismo no Brasil" 
- Dr. Milton Santos - geográfo, professor titular da FFLCHUSP e responsável, entre outras, por importante obra teórica sobre conceitos de paisagem e território e que ministrou a conferência "As novas concepções da paisagem"

As quatro conferências geraram grande impacto na platéia, provocando uma discussão de alto nivel entre os participantes.

Comunicações sobre Campos de Pesquisa - o ensino não pode ser desligado de uma produção teórico-metodológica que só pode ser obtida por meio de um processo sistemático de pesquisa. Esta no Brasil, à exceção do trabalho da FAUUSP, está bastante fragilizada, em função das dificuldades de trabalho existentes devido a fatores diversos (falta de recursos, tempo, bibliografia, etc.) e a inclusão do tema nos pareceu óbvia e natural.

Foram apresentados 11 trabalhos, sobre assuntos diversos, tendo os trabalhos de Claudio Goya "A história ou as fábulas dos jardins brasileiros" e de Carlos Valentim e Luis Emygdio Mello Filho (UFRJ) sido alvo de apreciação especial por parte da platéia.

Ao final da apresentação foi aberta uma mesa redonda e foram rediscutidas as apresentações de Vicente del Rio e Miranda $M$. Magnoli, dando-se ênfase à questão do objeto de trabalho do paisagista no urbano os espaços livres de edificação.

Plenária - A fase conclusiva do evento - foi preparada com cuidado, de modo a alcançarmos os resultados pretendidos. Os resultados dos diversos grupos de trabalho foram reunidos por uma comissão mista de participantes dos grupos e foram votados pelo coletivo, com os resultados já indicados. Ao final foi escolhida a Escola de Arquitetura e Urbanismo da USP São Carlos, como sede do III Encontro, que discutirá o seguinte tema: "Métodos de Ensino: Procedimentos e Resultados", buscando aprofundar as discussões do I ENEPEA, à luz dos resultados obtidos neste evento e da expe-riência desenvolvida nos anos de 95 e 96. 


\section{EVENTOS PARALELOS}

Foram organizados os seguintes acontecimentos:

1. Concurso Nacional de Estudantes - criado de modo a incentivar os trabalhos de projeto dos alunos de arquitetura e urbanismo nas questões paisagísticas. Foram estabelecidas 04 categorias de prê-mios nas áreas: Paisagem Urbana, Planejamento Paisagístico, Praças e Parques. Foram enviados e julgados 38 trabalhos provenientes de 15 escolas de todo o Brasil.

A comissão julgadora composta dos arquitetos Benedito Abbud (mestre pela FAUUSP), Fany Galender (mestranda da FAUUSP) e Maria Cecília Gorsky (presidente da ABAP), decidiram, após julgamento, a criação de menções honrosas devido a alta qualidade dos trabalhos apresentados, em quase todas as categorias. A premiação foi a seguinte:

\section{CATEGORIA PAISAGEM URBANA}

\section{Premiado:}

Título: Um suspiro para a Rua XV

Aluno: Daniela Slomp Busarello

Orientadores: Leticia Peret Antunes Hardt, Oscar Gomm Mueller e Paulo Chiesa

Escola: Pontifícia Universidade Católica do Paraná

Menção honrosa:

Título: Paisagem Urbana

Alunos: Daniel do Valle, Gerson Issao Yassumoto e Maurício Alexandre Mass

Orientadores: Leticia Hardt, Paulo Chiesa e Mara Paludo Escola: Universidade Federal do Paraná 


\section{CATECORIA ESPAÇO LIVRE}

Premiado:

Título: Praça "Architectonica Nobilis"

Aluno: Susan Honjo

Orientadores: Leticia Hardt

Escola: Pontifícia Universidade Católica do Paraná

Menção honrosa:

Título: Projeto para quadra habitacional no Grajaú: estudo paisagístico dos espaços livres junto às edificações Alunos: Breno Simão e Gabriela Ferreira Pimentel Orientadores: Mario Ceniquel e Vera Lucia Cardim Escola: Universidade Federal do Rio de Janeiro

\section{CATEGORIA PLANEJAMENTO AMBIENTAL}

\section{Premiado:}

Título: Antonina: Nos trilhos da baía a paisagem estruturando o ambiente urbano

Alunos: Gisele Medeiros, Larissa R. Peixoto, Luciane Pellegrino Barbosa, Renata Martins Oliveira e Viviane Nota Machado Orientadores: Leticia Hardt, Carlos Hardt e Eduardo Lagarrigue Escola: Pontifícia Universidade Católica do Paraná

Menção honrosa:

Título: Intervenção em Área Rural

Alunos: Cristiane Jerci Michel, Eduardo Silva, Katia Pimentel Koti e Tania Mara Souza

Orientador: Leticia Hardt

Escola: Universidade Federal do Paraná

Menção honrosa:

Título: VERde Vertentes

Alunos: Alexandre de Brito Muuga, Gabriela Negreiros Saback Vianna e Luis Felipe Xavier

Orientadores: Hortência Espallargas e Eliane Guaraldo Escola: Universidade Paulista - UNIP 
Categoria Parques: foram apresentados poucos trabalhos e nenhum teve o nível suficiente para ao menos uma menção honrosa. O tema no caso é pouco desenvolvido nas diversas escolas e na minha opinião um dos mais complexos entre os referentes ao projeto de paisagismo.

Todos os concorrentes foram expostos no Salão Caramelo - o principal espaço da FAUUSP.

2. Exposição didática - foi criada a possibilidade de cada escola enviar 02 painéis demonstrando uma síntese da sua produção na área de paisagismo. Esta exposição montada no mesmo espaço da exposição do concurso de alunos e reuniu trabalho de 10 escolas.

3. Exposição da Pesquisa "Quadro do Paisagismo no Brasil" mostrando uma síntese dos resultados obtidos nos seus primeiros 18 meses de atividades. Esta pesquisa coordenada por mim e patrocinada pelo CNPq, Fapesp e FAUUSP, visa montar uma síntese da produção paisagística brasileira, especialmente no tocante a espaços públicos - praças, parques e calçadões. Os painéis apresentados em número de 08 , mostraram um quadro geral da evolução do paisagismo no Brasil e alguns dos principais projetos já desenvolvidos no país, nos séculos 19 e 20. Foi montada no salão do auditório da FAUUSP.

4. Mostra de vídeos - apresentada nos intervalos das sessões, no auditório da FAUUSP, exibiu trabalhos da FAUUSP, da UFPR, da PUC-PR, da UNIFEC e da UNIP.

5. Feira de livros-organizada com o apoio de editoras e livrarias importantes, como Studio Nobel, Pini, Edusp e Projeto, que trouxeram as últimas novidades na área e afins, sendo montada no saguão do auditório da FAUUSP Na oportunidade foi lançado o número 07 da Revista Paisagem e Ambiente - Ensaios, editada pela FAUUSP - Grupo de Disciplinas Paisagem e Ambiente, a única revista científica a tratar especificamente do assunto no Brasil, e o software "Paisagem" elaborado pelo arquiteto/mestrando FAUUSP, Jonathas P.M. da Silva. 


\section{AVALIAÇÃO}

O evento superou as minhas expectativas em termos de seriedade, profundidade e interesse dos participantes, que se enfocaram o temário nas suas discussões chegando às conclusōes já apontadas.

Deste ponto de vista foi um sucesso e assim concordam meus colegas da Comissão Organizadora, as professores Vera Tângari e Leticia Hardt, e da Comissão Assessora, os professores Helena N. Degreas, Maria Angela F. P. Leite, Davi Chermann e Paulo Chiesa.

Foi um evento pequeno, com 105 participantes, um número ligeramente menor ao obtido no I ENEPEA realizado em 1994 no Rio de Janeiro. Paralelamente foi um evento mais abrangente em termos nacionais, pois tivemos a presença de colegas/professores de diversos Estados que não tinham comparecido no evento anterior como os professores de Salvador (UFBA), Viçosa (UFVI) e outros mais, estando ainda presentes professores de todas as escolas participantes do I ENEPEA.

Foi também um evento restrito, específico, devido ao temário, fato este que fez reunir um contingente expressivo de pesquisadores e professores de paisagismo no Brasil, não atraindo um público de cu-riosos, mas somente um público interessado, que trabalha e trabalhará para o aprofundamento das questões paisagísticas nacionais.

Deu-nos, a mim e a todos, a certeza de que a questão do ensino está em um processo crescente de amadurecimento, e que a pesquisa ainda é um fato isolado e disperso, estando concentrada no eixo Rio-São Paulo, em especial nos trabalhos vinculados aos cursos de pós-graduação mestrado e doutorado da FAUUSP Este é assunto a ser objeto de novas e constantes discussões, já que para seu desenvolvimento são muito grandes as dificuldades, tanto em nível institucional - escolas, como no nível de agências e fontes de financiamento. 
Como informação geral temos o seguinte quadro:

1. número de participantes: 105 .

2. número de professores participantes: 62.

3. número de pesquisadores participantes: 17

4. número de outros participantes: 26.

5. número de entidades/escolas representadas: 36 .

Concluindo podemos afirmar que este evento só teve o resultado altamente positivo devido às seguintes pessoas e entidades que o apoiaram diretamente.

Da FAUUSP diretoria e vice-diretoria professores Júlio Roberto Katinsky e Élide Monzéglio.

Francisca de Souza Lima - secretária do evento e do Grupo de Disciplinas Paisagem e Ambiente.

Assessoria de Eventos Culturais - na pessoa das senhoras Lina Rosa e Neusa Brandão.

Do Laboratório de Progração Gráfica - em especial na pessoa do arquiteto José Tadeu de Azevedo Maia.

Dos arquitetos Margareth Serra e Cesar Campos e dos alunos Luis Brandrão e Claudia Borges na montagem das exposições didáticas e da FAUUSP.

Da ABAP - pela sua presidente a arquiteta Maria Cecilia Gorsky. Das seguintes escolas e instituições:

- UNIP - Universidade Paulista na divulgação e publicação de folders, cartazes e circulares.

- Universidade São Marcos - na publicação dos anais.

- Fapesp - auxílio financeiro. 
- CNPq - auxílio financeiro.

- Pró-Reitoria de Extensão Cultural USP - auxílio financeiro.

Da Comissão Organizadora - professoras Leticia Hardt (UFPR e PUC-PR) e Vera Tângari (UFRJ) esta última exercendo de fato a vice-presidência/coordenadoria do evento

Da Comissão Assessora - professores Helena Degreas (UNIP e São Marcos) - juntamente com a professora Maria Angela Faggin Pereira Leite nossa principal assessora - Paulo Chiesa (PUC-PR e UFPR) e Davi Chermann (apoio editorial para os anais). 